\title{
The impact of high-sensitive troponin levels during liver transplantation on postoperative course: prelimilary results
}

\section{Vilchez Monge AL, Hernández I, Garutti I, Olmedilla L, Jimenez de la Fuente C, Perez-Peña JM.}

\section{Background and Goal of study}

\section{Materials and methods}

184 adult patients undergoing LT

Excluded: patients undergoing retransplantation and those with elevated basal troponins.

\section{MONITORING :}

Althought recent studies have demonstrated that an increase of perioperative biomarkers of myocardial injury such as highsensitivity troponin T (HS- TnT) is related with poor postoperative outcome, there are no studies analyzing intraoperative values of such markers in population of liver transplant recipients.

The goal of our study was to investigate what is the impact of intraoperative elevation of TnT on early postoperative course after liver transplantation.
1. Haemodynamic mesurements with PiCCO catheter. (Pulsion Medical Systems SE)

2. Analysis - HS-TnT (Roche)

3 KEY MOMENTS: - hepatic disection - anhepatic phase - after graft implantation

- HS- Tnt $>42 \mathrm{ng} / \mathrm{L} \rightarrow$ highly suggestive of myocardial injury

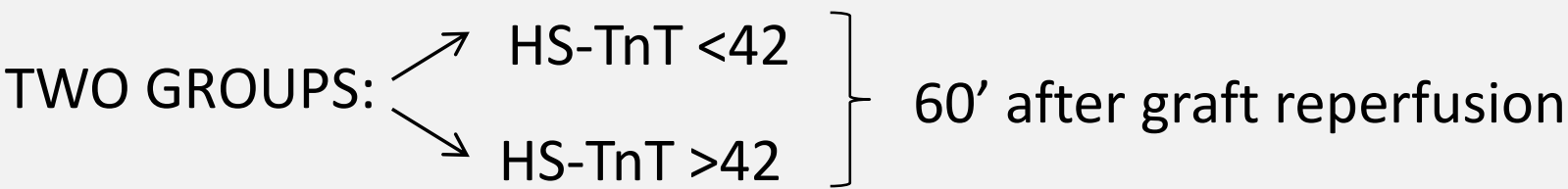

Statistical analysis: U- Mann-Whitney - $\mathrm{Chi}^{2}$.

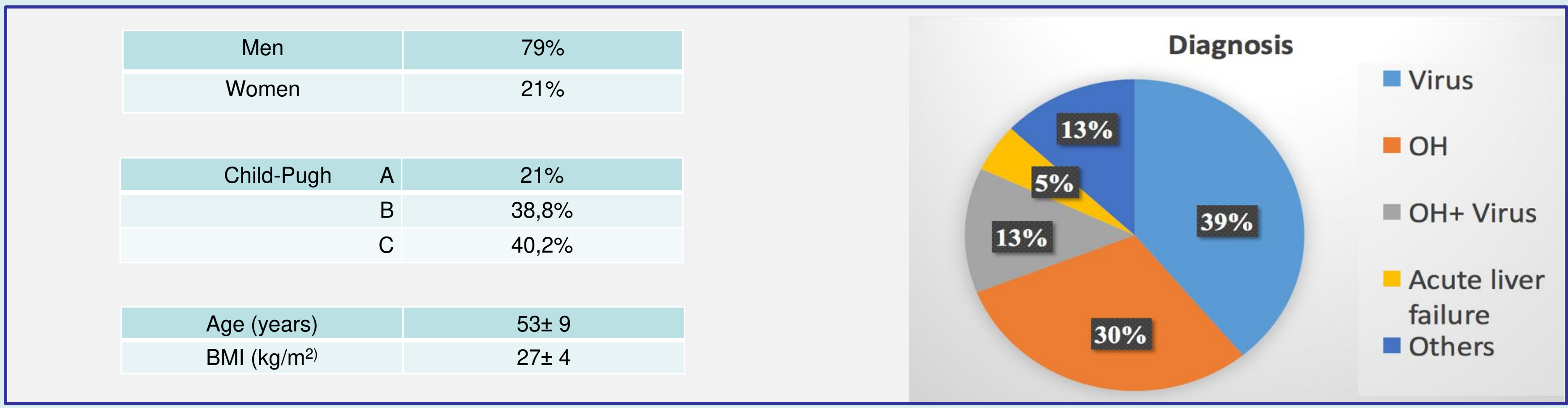

\section{Results}

$\underline{33.8 \%}$ patients $\rightarrow$ HS-Tnt $>42 \mathrm{ng} / \mathrm{L}$ at 60 minutes after graft reperfusion

$$
\text { Group HS-TnT > 42 } \begin{cases}1 & \text { mechanical ventilation-MV (hours) } \\ 1 & \text { ICU stay (days) }\end{cases}
$$

\begin{tabular}{|c|c|c|}
\hline Hs- Tnt (ng/L) & Mechanical ventilation (hours) & ICU stay (days) \\
\hline$>42$ & $32,6(12,7-52,5)$ & $4,4(3,4-5,3)$ \\
\hline$<42$ & $18,7(12,9-24,5)$ & $3,5(3,1-3,9)$ \\
\hline & $p=0.028$ & $p=0.036$ \\
\hline
\end{tabular}

No clinical findings suggesting myocardial injury were found in the intraoperative and early postoperative course (Cardiac Index, CFI, and ECGs showed no significant changes).

\section{Conclusions}

1-Troponin elevation during liver transplantation predicts early complicated postoperative course (prolonged mechanical ventilation and ICU stay).

2- It seems to have prognostic value enabling prediction of clinical deterioration before other measurable derangements occur, and allows for earlier adaptation of anaesthetic management to patient individual requirements. 